\title{
RANCANG BANGUN SISTIM PENGISIAN BATERAI OTOMATIS GENSET TIPE RIDER DI KAMPUS KEMARITIMAN POLNES SAMARINDA
}

\author{
Rusman $^{1)}$, Shanty ${ }^{2)}$ \\ Staf Pengajar Jurusan Kemaritiman Politeknik Negeri Samarinda ${ }^{1,2)}$ \\ Jl. Kapal Selam 1 No. 10 RT. 17 Loktuan Bontang \\ E-mail: azisrusman@gmail.com
}

\begin{abstract}
ABSTRAK
Sekarang ini, sering terjadi pemadaman listrik oleh PLN yang banyak mengganngu kegiatan masyarakat khususnya kampus. Penyediaan sumber tenaga listrik memegang peranan penting dalam bernagai aspek kehidupan. Oleh sebab itu, pasokan tenaga listrik diharapkan dapat tersedia terus-menerus (kontinyu).

Saat ini di kampus Kemaritiman Politeknik Negeri Samarinda terdapat pembangkit cadangan yang biasa disebut generator set. Apabila suplai PLN padam maka genset dioperasikan sebagai sumber tenaga listrik sehingga tidak mengganngu aktivitas yang sedang berlangsung. Pada saat ini, genset tidak hanya digunakan di industri saja, melainkan telah dipakai di kampus serta instalasi rumah tinggal.

Dalam pengoperasian sebuah genset, jarang ditemukan pengontrolan genset secara otomatis yang mana dalam hal ini untuk genset yang ada di kampus Kemaritiman Politeknik Negeri Samarinda, bagaimana merancang dan membuat sistem pengisian aki genset secara otomatis sehingga pada saat PLN padam maka genset bisa distarter. Kenyataan yang ada dilapangan sekarang pada saat PLN padam aki genset kondisinya soak (tegangannya berkurang ) sehingga tidak bisa menyalakan genset sehingga semua aktivitas terhenti.

Dalam penelitian ini, penulis mencoba menerapkan sistem pengisian otomatis pada aki genset sehingga pada saat ada pemadaman listrik dari PLN, genset tetap bisa dinyalakan karena aki genset selalu penuh dan siap dioperasikan setiap saat.
\end{abstract}

Kata Kunci: Aki, Genset, inverter, charger otomatis

\section{PENDAHULUAN}

Dengan semakin tinggi tingkat konsumsi energi listrik ini maka pihak penyedia energi listrik dalam hal ini adalah PLN (Perusahaan Listrik Nega-ra) sebagai pengolah kelistrikan nasio-nal semakin tahun semakin meningkat. Belakangan ini fenomena konsumsi energi listrik oleh para konsumen di-tanggapi oleh PLN dengan memba-ngun beberapa pusat pembangkit baru, sehingga untuk pembangunan memerlu-kan investasi yang sangat besar. Hal ini mendorong PLN memerlukan program kepada masyarakat tentang penghematan energi listrik dengan berbagai cara diantaranya adalah 17:00-22:00, se-hingga pada jam-jam ini menggunakan energi listrik sangat besar. Dan dalam istilah kelistrikan disebut sebagai beban puncak.

Salah satu alternatif energi listrik selain PLN adalah energi dari genset yang mana sangat dibutuhkan jika PLN padam, agar tidak terganggunya pekerjaan dikantor atau dikampus. Yang menjadi permasalahan adalah pada saat mem-butuhkan energi pada genset dan ternyata baterai dari genset tersebut soak atau teganngannya turun sehingga tidak dapat menstarter genset tersebut.

\section{LADASAN TEORI \\ Baterai Akumulator}

Akumulator (accu, aki) adalah sebuah alat yang dapat menyimpan energi (umumnya energi listrik) dalam bentuk energi kimia. Contoh-contoh akumulator adalah baterai dan kapasitor. Pada umumnya di Indonesia, kata akumulator (sebagai aki atau accu) hanya dimengerti sebagai "baterai" mobil. Sedangkan di bahasa Inggris, kata akumulator dapat mengacu kepada baterai, kapasitor, kompulsator, dll. Akumulator (aki). Akumulator termasuk ke dalam jenis sel sekunder, artinya sel ini dapat dimuati ulang ketika muatannya habis. Ini karena reaksi kimia dalam sel dapat dibalikkan arahnya. Jadi sewaktu sel dimuati, energi listrik diubah menjadi energi kimia, dan sewaktu sel bekerja, energi kimia diubah menjadi energi listrik. hidrogen yang dekat dengan lempeng negatif 
bersatu dengan ion S04 pada lempeng negatif membentuk molekul asam sulfat. Sedangkan ion oksigen yang bebas bersatu dengan tiap atom $\mathrm{Pb}$ pada lempeng positif membentuk $\mathrm{Pb} 02$. Reaksi kimia yang terjadi adalah : $2 \mathrm{PbS} 04+2 \mathrm{H} 20$----> PbO2 + Pb + 2H2SO2.

\section{Charger}

Charger merupakan salah satu komponen yang sangat penting untuk memberi supply tenaga salah satu con-tohnya adalah pada sepeda motor, untuk itu perlu perhatian khusus agar peng-gunaan atau pemenfaatan aki dapat seca-ra maksimum. Dengan teknik yang telah di tentukan dalam pembahasan ini, sekilas dapat diketahui bahwa dengan proses charge maka sebuah aki dapat diman-faatkan secara maksimum.[6] Untuk mengetahui waktu dalam proses pengisian aki, dapat menggunakan perhitungan diba-wah ini:

-Lama pengisisan Arus: $\mathrm{Ta}=\frac{A H}{A}$

Keterangan :

$\mathrm{Ta}$ = Lamanya pengisisan arus (jam)

$\mathrm{Ah}=$ Besarnya kapasitas accu (Ampere hours)

$\mathrm{A}=$ Besarnya arus pengisisan ke accu (Ampere)

Lama pengisian Daya: $\mathrm{Td}=\frac{A h}{A}$

Keterangan :

$\mathrm{Td}=$ Lama pengisian daya (jam)

Daya $\mathrm{Ah}=$ Besarnya daya yang didapat dari perkalian Ah dengan besar teganggan accu (Watt hours)

Daya $\mathrm{A}$ = Besarnya daya yang didapat dari perkalian A dengan besar tegangan accu (watt)

Cas ini adalah jenis fullwave rectifier regulator, outputnya $14.8 \mathrm{Vdc} 5 \mathrm{Amp}$, dan bukan jenis otomatis, sehingga ketika mau ngecas diperkirakan dulu waktunya, rumusnya

$$
\mathrm{T}=\mathrm{I} \text { accu } / \mathrm{I} \text { cas }
$$

Keterangan :

$\mathrm{T}$

$\mathrm{I}$ accu = arus aki ( Ah )

I pengisian $=$ arus output

pengisian (A)

Contoh:

a. Untuk pengisian aki 50 Ah $\Rightarrow \mathrm{T}=50 \mathrm{Ah} / 5 \mathrm{~A}=10 \mathrm{jam}$

b. Untuk pengisian aki $100 \mathrm{Ah}$ $\Rightarrow \mathrm{T}=100 \mathrm{Ah} / 5 \mathrm{~A}=20 \mathrm{jam}$

\section{Inverter}

Inverter adalah perangkat elektronika yang dipergunakan untuk mengubah tegangan DC (Direct Current) menjadi tegangan AC (Alternating Curent). Output suatu inverter dapat berupa tegangan AC dengan bentuk gelombang sinus (sine wave), gelombang kotak (square wave) dan sinus modifikasi (sine wave modified). Sumber tegangan input inverter dapat menggunakan battery, tenaga surya, atau sumber tegangan DC yang lain. Inverter dalam proses konversi tegangn DC menjadi tegangan AC mem-butuhkan suatu penaik tegangan berupa step up transformer. Contoh rangkaian dasar inverter yang sederhana dapat dilihat pada gambar berikut. Contoh Rangkaian Inverter Sederhana inverter dc ke ac,prinsip kerja inverter,jenis inverter,tipe inverter,output in-verter,sine wave inverter,square wave inverter,teori inverter,inverter adalah,inverter 1 fasa,inverter 3 fasa,modified sine wave inverter, gelombang output inverter, fungsi inverter, kategori inverter, karkteristik inverter,input inverter,inverter $12 \mathrm{v}$, inverter $24 \mathrm{v}$, dc to ac inverter,inverter Jenis - Jenis Inverter DC Ke AC Berdasarkan jumlah fasa output inverter dapat dibedakan dalam : Inverter 1 fasa, yaitu inverter dengan output 1 fasa. Inferter 2 fasa, yaitu inverter dengan output 3 fasa. Inverter juga dapat dibedakan dengan cara pengaturan tegangan-nya, yaitu : Voltage Fed Inverter (VFI) yaitu inverter dengan tegangan input yang diatur konstan Current Fed Inverter (CFI) yaitu inverter dengan arus input yang diatur konstan Variable $\mathrm{dc}$ linked inverter yaitu inverter dengan tegangan input yang dapat diatur Berdasarkan bentuk gelombang output-nya inverter dapat dibedakan menjadi : Sine wave inverter, yaitu inverter yang memiliki tegangan output dengan bentuk gelombang sinus murni.

\section{Genset}

Salah satu pengegrak mula pada generator set adala mesin diesel, ini dipergunakan untuk menggerakkan rotor $=$ bemarpeorgissieming menghasilkan Ggl. Mesin Diesel termasuk mesin kalor yang mengubah tenaga panas menjadi tenaga gerak. Tenaga panas diperoleh dari proses pembakaran solar dengan bantuan oksigen dari udara. Gas hasil pembakaran itu dipergunakan untuk meng-gerakkan torak secara gerak translasi.Gerak translasi ini diteruskan ke batang peng-hubung (connectiing 
road) dengan proses engkol ( crank shaft) sehingga menghasilkan gerak berputar pada poros engkol.

Demikian juga sebaliknya gerak rantai dari poros engkol dan rotor disambung secara kopling. Dengan adanya rotor yang diputra oleh mesin diesel, sedangkan kepada gulungan rotor diberikan arus listrik searahm, maka pada pihak stator terbangkit out put tegangan : bolak balik. Untuk mendapatkan putaran yang stabil diperlukan sistem Governor ( pengaturan putaran ) dan VR ( Voltage Regulator).

\section{Diesel sebagai Pengerak Mula}

Syarat-syarat untuk mendapatkan diesel sebagai penggerak mula yang baik diperlukan:

a. Bahannya dari logam yang berkualitas baik

b. Sistem pengaturan bahan bakar dan bahan bakarnya sendiri (solar) harus baik dari tangki utama, tangki harian dalam pompa injeksi ( injection pump) sampai masuk dalam pembakaran silinder.

c. Sistem pelumasan, jenis oli, seluruh sistem pelumasan silinder harus tepat dan baik

d. Sistem pendinginan yang baik yaitu pendinginan dengan udara maupun dengan air.

e. Sistem penyaluran udara yang baik, udara yang dipergunakan pembakaran bahan bakar dalam silinder harus dalam perbandingan yang tepat

f. Generator dan perlengkapannya terma-suk pengatur tegangan dan frekuensi harus baik

g. Panel-panel yang berisi rangkaian kontrol, baik untuk kontrol diesel maupun Generator selalu bekerja normal.

h. Sistem starter harus baik agar mesin selalu siap untuk beroperasi apabila hendak dioperasikan

i. Perawatan dan pemeliharaan yang baik dan teratur akan menjadikan tercapainya tujuan pemeliharaan tersebut.
HASIL DAN PEMBAHASAN

Hasil rancangan dan pembuatan alat

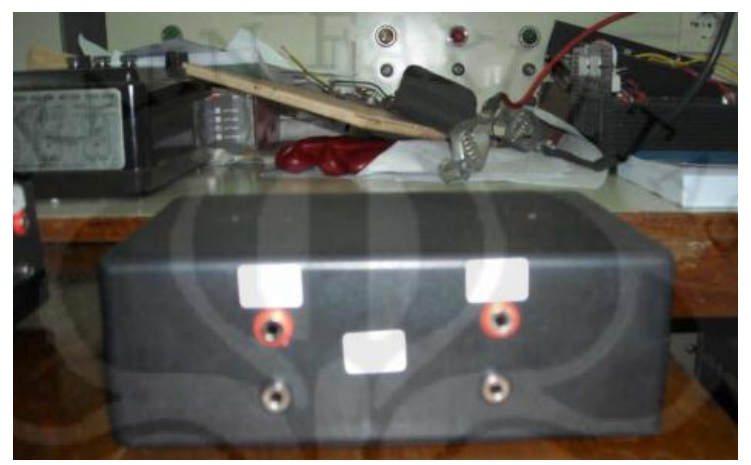

Gambar 1. Rancangan Alat

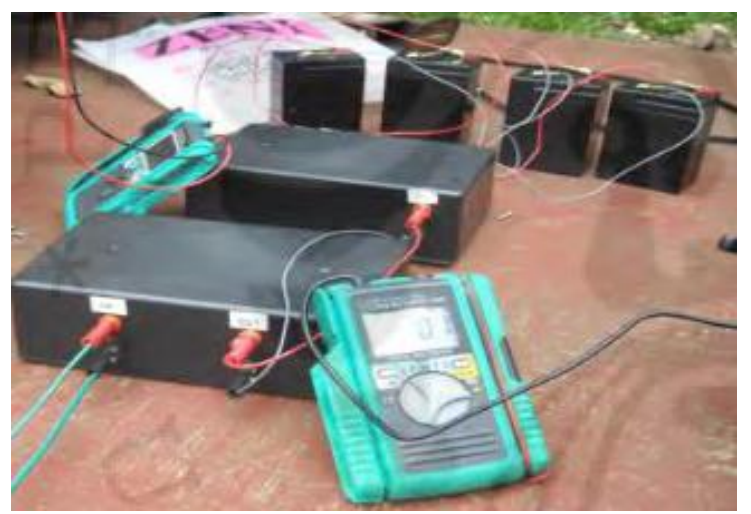

Gambar 2. Proses Pengujian Alat

Hasil Pengujian

Untuk mendapatkan data yang akurat dari rangkaian sistim yang telah dibuat :

a. Untuk mengetahui berapa besar tegangan yang dihasilkan saat pengi-sian

b. Untuk mengetahui berapa besar tegangan yang hilang saat pengo-songan. Pengujian pada aki dapat dilihat pada tabel 5.1

Tabel 5.1 Hasil Pengujian Lapangan

\begin{tabular}{|l|l|}
\hline JAM & TEGANGAN (V) \\
\hline 1 & 10,20 \\
2 & 10,38 \\
3 & 10,56 \\
4 & 10,72 \\
5 & 10,90 \\
6 & 11,08 \\
7 & 11,26 \\
8 & 11,44 \\
9 & 11.64 \\
10 & 12.02 \\
& \\
\hline
\end{tabular}

Sumber : Data Lapangan 
Dalam hal pemakaian aki dapat mengalami pengosongan tegangan tanpa beban. Data hasil pengujian aki pada tabel 5.2 :

\begin{tabular}{|l|l|}
\hline HARI & TEGANGAN $(\mathrm{V})$ \\
\hline 1 & 12,05 \\
2 & 11,87 \\
3 & 11,74 \\
4 & 11,60 \\
5 & 11,47 \\
6 & 11,34 \\
7 & 11,21 \\
8 & 11,08 \\
9 & 10,95 \\
10 & 10,82 \\
\hline
\end{tabular}

Sumber : Data Lapangan

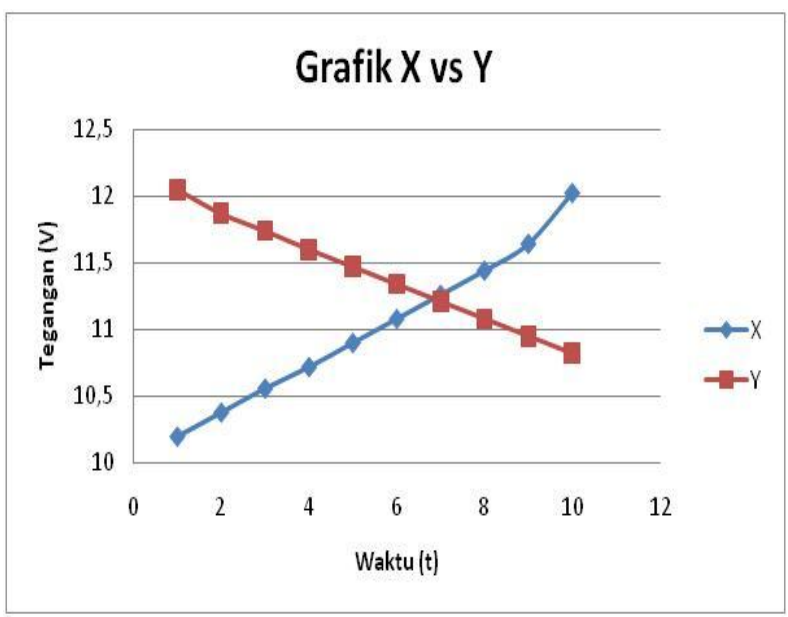

Gambar 3. Grafik X dan $Y$

Sumber: data olahan

\section{PEMBAHASAN}

Berdasarkan hasil olahan data menunjukkan bahwa pada pengambilan data sebanyak sepuluh sampel dan ini menunjukkan bahwa pengisian aki cen-derung naik secara linear dengan pengisian selama 10 jam dimana baterai yang diisi mempunyai kapasitas 100 AH dan chargernya 5 A . Kemudian pa-da saat pengosongan dengan tanpa beban akan cenderung turun dengan secara linear juga artinya apabila tanpa pemakaian maka aki tersebut cenderung akan menurun dayanya. Dan diasum-sikan bahwa PLN tidak akan padam selama 13 hari sehingga daya dapat terisi secara otomatis dan siap dibebani kapan pun.

\section{KESIMPULAN}

Dari hasil penelitian dan hasil perhitungan serta pembahasan makadapat disimpulkan bahwa energi yang hilang sangat berpengaruh terhadap daya baterai. Kemampuan untuk starter genset menjadi lemah. Adanya rancang bangun alat ini akan menstabilkan arus/daya yang tersimpan pada baterai sehingga kapan pun listrik padam energi baterai masih mampu untuk men-starter genset.

\section{DAFTAR PUSTAKA}

1. Akhmad Iswandi Lubis 2011, Rancang Bangun Rangkaian Charger Sebagai Sumber Lkistrik Cadangan Pada Power Supply, Medan

2. Andi M. L.Tobing 2013. Rancang Bangun Sistem Suplai Daya Listrik 900 watt Untuk Rumah Tinggal, Lampung.

3. Bishop, Owen. 2004. Dasar-dasar Elektronika. Jakarta. Erlangga.

4. Dwi Sunar Prasatyono.Belajar Sistem Cepat Elektronika. Penerbit. ABSOLUT. Maret 2003.

5. M. Saddam Rizky. 2010. Rancang Bangun Sistem Otomatisasi Penerangan Yogyakarta.

6. http://bayupancoro.wordpress.com /2009/ $\underline{01 / 20 / \text { current-transformer-ct/ }}$

7. http://bengkelmobilnet.blogspot.com /2010/09/fungsi-aki.html

8. http://teknologi.kompasiana.com/ otomotif/2010/12/26/baterai-pada- mobil/

9. http://blognyagadget.blogspot.com /2011/04/fungsi-charger-dan-jenis- jenischarger.ht 